\title{
So you thought mountain ranges were complicated
}

\author{
from Myrl F. Beck
}

REMEMBER the time when it was thought that the major features of the Earth's crust were riveted in place as securely as armour plates on a battleship? It took courage to be a tectonic theorist, but life may have been easier for the quadrangle-mapper. In those days, crustal blocks mostly moved up and down, or perhaps a few tens of kilometres laterally at most, so one naturally looked for solutions to local geographical problems in one's own backyard. If granitic debris suddenly appeared in a sedimentary section, it meant uplift of the granitic batholith immediately across the valley. There was no need to complicate life by looking any further.

Even with the advent of early plate-tectonic theory the quadrangle-mapper's task was still much the same; unless his map area spanned a major suture, the several parts of his study area could still be assumed always to have been close together, barring a few highly unusual, and geologically easily recognizable, circumstances. But time has complicated this simple picture. In the past decade, a combination of geology and paleomagnetism has shown that at least one orogenic belt (the North American Cordillera) is a moraine of crustal fragments, many with oceanic affinities, transported intact from points of origin hundreds or thousands of kilometres away. Geological studies showed that many adjacent Cordilleran crustal blocks are too unlike one another in stratigraphy and structural history to have evolved in juxtaposition, and that some of these crustal blocks, or terranes, are wholly exotic to North America. To settle this issue, paleomagnetism has provided dramatic evidence of ultra-long-distance transport of crustal blocks.

This microplate model is familiar to many geologists. Orogenesis and the growth of the continent are held to have been more the result of collision and offscraping of these prefabricated crustal elements than of subduction of the oceanic plates upon which they rode. The model also holds that, once attached to North America, many of these terranes were disrupted by strike-slip faulting; the resulting fragments are now distributed along the continent's edge, placed there by a process that might be termed tectonic longshore drift. Large rotations about vertical axes also may occur during this stage. Because subduction along the western edge of North America has been north-oblique since at least the late Mesozoic, transport and rotation in the Cordillera seem to have been mostly northward and clockwise, respectively. The scale of the process is hotly debated; some pieces of the Cordilleran mosaic are as small as a house, but others clearly are at least as large as, say, Vancouver Island.

Nevertheless, it still seems to be true that mountain belts are a product of plate interaction, and that they are built at plate margins, usually at the edge of a continent. It should follow that major events in the tectonic history of mountain belts reflect major changes in the behaviour of plates. It should, therefore, be possible to investigate the nature of orogenic cause-andeffect by observing correlations between important tectonic transitions in a mountain belt (as from overthrust to extensional faulting) and events along the plate margin (as, for instance, a change from rapid to slow convergence).

But a mountain belt is an exceedingly complex recorder. Tectonic events overwrite earlier deformations on the same piece of crust without completely erasing the earlier record - thereby making both records hard to interpret. Also, continental crust in an orogenic belt varies enormously in thickness, age, and physical properties from place to place; it seems hopelessly optimistic to assume that the same orgenic response will always follow a particular plate-tectonic event. The timing of tectonic events is a further problem. Such 'events' last several millions or tens of millions of years, and most are complex and progressive - that is, they involve several geological processes acting simultaneously or in sequence. It is hard to know when an 'event' actually starts or stops. Thus, correlations with plate-tectonic phenomena are bound to be difficult to make, and often will not be particularly convincing.

Still more trouble arises because of the nature of the record of relative plate motions. In the Cordilleran example, three oceanic plates (Farallon, Kula, Pacific) and one continental plate (North America) are involved. According to most plate models, direct Pacific-North America interaction has been a factor in Cordilleran tectonics only for the last $30 \mathrm{Myr}$ or so. The chief culprits have been the Farallon and Kula plates, of which, respectively, very little and nothing remain. We deduce the relative motion histories of these two plates from what we hope are mirror-image anomaly patterns recorded on the Pacific plate - thereby putting ourselves explicitly at the mercy of the symmetrical spreading hypothesis of plate tectonics. Likewise, many models make use of the trends of the Hawaiian Islands and the Emperor Seamount chain to deduce absolute motion of the Pacific plate. Any inaccuracy in the notion that hotspots are fixed relative to each other thus transfers directly to our plate reconstructions. Finally, it has recently been shown that inaccuracies in specifying stage poles for finite rotations increase with the age of the pole, and may become quite large. This means that some of our Mesozoic reconstructions may be seriously in error.

But where was the Kula-Farallon-North America triple junction during the late Mesozoic and early Tertiary? Since the relative motions of Kula-North America and Farallon-North America were quite different at times, the triple junction ought often to have separated regions of distinctly different tectonic style. It may have moved up and down the coastline rather erratically, however. Perhaps the geology will help us locate the triple junction and thereby improve the plate models. The tectonic consequences of transferring large exotic terranes from the oceanic to the continental crust are poorly known; in particular the effect on plate motions is uncertain.

Whether or not the Cordilleran microplate model can be applied to other mountain belts remains to be seen. For the present, pity the poor quadrangle-mapper. No longer can he assume that the batholith across the valley was there when his sedimentary section began recording its influx of granitic debris; without definite paleomagnetic or geological evidence to the contrary, it might instead have been part of, say, Sumatra.

Myrl F. Beck is Visiting Professor in the Department of Geological Sciences, Northwestern University, Evanston, Illinois 60201, USA.

\section{0 years ago}

The Edible Mollusca of Great Britain and Ireland. With Recipes for Cooking Them. By M. S. Lovell.

THE primary object of the author is to call attention to the qualities and merits of many kinds of shell-fish which are as nutritious as others which are generally known, but which are rarely met with in our markets, or are only used locally for food, while the proper modes of cooking them are scarcely known. Accordingly all the known species of edible shell-fish on our coasts are here described in succession. This alone would make the volume of great use at a time when we are going to the uttermost ends of the earth for the sources of our food-supply. But when we add that the writer has collected from the most varying sources a mass of curious lore about shell-fish, their uses, and the mode of catching them in various parts of the globe, their medicinal properties, the popular superstitions about them, \&c., it will be perceived that this is much more than a work on natural history plus a cookery-book. Of all the many uses of snails, the strangest perhaps is that discovered by the London adulterator. They are much employed, the author assures us, in the manufacture of cream, being bruised in milk and boiled, and a retired milkman pronounced it the most successful imitation known!

From Nature 31, 124, 11 December 1884. 